\title{
Perspectivas
}

ISSN-L: 2215-4728

DOI: http://dx.doi.org/10.15359/rp.23.6

http://www.revistas.una.ac.cr/perspectivas

N. ${ }^{\circ}$ 23. Julio-Diciembre, $2021 \cdot$ pp. 1-15

\section{Entrevista con Rotsay Rosales Valladares: repensar la Educación Cívica en Costa Rica}

\author{
Interview with Rotsay Rosales Valladares: \\ rethinking Civic Education in Costa Rica
}

\section{Maximiliano López López*}

Fecha de recepción: 13/05/2021

Resumen: En esta entrevista el Dr. Rotsay Rosales Valladares se refiere a varios aspectos de la Educación Cívica actual, los cuales, a su juicio, explican la pasividad y la resignación que se transmite a los jóvenes desde esta asignatura escolar. Para él, este proceso educativo, lejos de combatir el modelo económico del capitalismo global con ciudadanos críticos y con alto compromiso cívico, más bien lo refuerza con la promoción de consumidores dóciles y acríticos. Por ello, y como una propuesta axiológica, el Dr. Rosales Valladares propone la necesidad de una Educación Cívica que contribuya al
Abstract: In this interview Dr. Rotsay Rosales Valladares talks about current Civic Education, which, in his opinion, explains the passivity and resignation that is transmitted to young people. Dr. Rosales Civic Education reinforces the promotion of docile and uncritical consumers, instead combating the economic model of global capitalism with critical citizens with high civic commitment, that's Why Dr. Rosales Valladares, proposes an axiological proposal, in order to Civic Education that contributes to the transition from this post-democratic liberal society to a post-liberal democratic society and country.

* Costarricense. Máster en Historia Aplicada y Máster en Pedagogía con énfasis en Atención a la Diversidad. Profesor e investigador en la Escuela de Historia de la Universidad Nacional (UNA), Sede Central Omar Dengo, Heredia, Costa Rica. Participa en la Red Centroamericana de Investigación y Docencia en Estudios Sociales y Ciudadanía Crítica (RECIDEC). Actualmente cursa el Doctorado en Gobierno y Políticas Públicas en la Universidad de Costa Rica (UCR), San José, Costa Rica. Correo electrónico: maximilian.lopez.lopez@una.cr. ORCID: https://orcid.org/0000-0003-3175-1731. 
tránsito de esta sociedad liberal posdemocrática, a una sociedad y un país democrático posliberal.

Keywords: Civic Education; citizenship State; Social Studies; Costa Rica.

Palabras claves: ciudadanía; Educación Cívica; Estado; Estudios Sociales; Costa Rica.

\section{Sobre el entrevistado}

Dr. Rotsay Rosales Valladares. Costarricense. Politólogo. Obtuvo su doctorado en Ciencias Sociales por la Facultad Latinoamericana de Ciencias Sociales, FLACSO, con su tesis sobre La institucionalización, democratización y transparencia interna de los partidos políticos en Costa Rica (2008). El Dr. Rosales tiene como áreas de especialización, partidos políticos, sistema de partidos, democracia, procesos electorales y teoría política, entre otros. Desde el 1994, es profesor de la Escuela de Ciencias Políticas de la Universidad de Costa Rica y, desde 1997, del Postgrado Centroamericano de Ciencias Políticas. Es investigador del Centro de Investigaciones y Estudios Políticos (CIEP) de la Universidad de Costa Rica. Ha sido profesor invitado en la Universidad Rafael Landívar, en Guatemala; también en la Universidad Nacional Autónoma de Honduras. Fuera de la región centroamericana ha sido conferencista y profesor invitado en la Universidad de Salamanca, en Santiago de Compostela y en la Universidad de Navarra, España. Entre sus producciones atinentes al campo de la Educación Cívica y de los Estudios Sociales se pueden citar

2008. "El sinuoso camino de la reforma electoral en Costa Rica". En Tendencias y perspectivas de la reforma electoral en América Latina; Cuadernos de la CEPAL, N. ${ }^{\circ} 54$.

2012. En coautoría con Manuel Rojas Bolaños; Poder, política y democracia. Cuadernos didácticos sobre teoría y práctica de la democracia (1). CIEP-UCR. https://www.corteidh.or.cr/tablas/28806.pdf

2012. En coautoría con Manuel Rojas Bolaños; Representación, partidos políticos y procesos electorales. Cuadernos didácticos sobre

teoría y práctica de la democracia (2). CIEP-UCR. https://www.iidh ed.cr/capel2016/media/1238/serie-cuadernos-didacticos-representacion-pp-y-procesos-electorales-no-2.pdf

2014. En coautoría con Harry Brown Araúz: "Cambiar todo para que nada cambie: los inside-outsiders de América Central". En Revista Contextualizaciones Latinoamericanas 6 (11). https://www.revistas. una.ac.cr/index.php/perspectivas/article/view/11276/15372

2015. "Problemas de la representación política y de los partidos políticos en Costa Rica: Oportunidad para un diálogo social reconstitutivo". Revista de Derecho Electoral (20).

2018. "Costa Rica: volatilidad, fragmentación, shock religioso y decisiones de último minuto". En Nuevas campañas electorales en América Latina. Konrad Adenauer.

\section{Entrevista}

Maximiliano López (ML): Para entrar en materia quisiera primero plantear un par de preguntas contextuales. La primera se refiere a la coyuntura socioeconómica, política y sanitaria que estamos experimentando. Aunque ciertos aspectos claramente vienen, desde 1990 algunas personas señalan, en referencia a ciertas políticas, que este contexto amenaza los cimientos democráticos construidos en Costa Rica a lo largo del tiempo. En correspondencia con esto y con lo que hemos vivido en las últimas dos décadas ¿Cómo ve usted la reacción del pueblo costarricense? en esencia ¿cree que la ciudadanía, o el pueblo en forma más general, es consciente de lo que está ocurriendo?

Rotsay Rosales Valladares (RRV): Existe la tentación a decir que no, que no hay una toma de conciencia que se traduzca, además, en acciones que permitan tener una visión o un panorama más optimista. Y por optimista me refiero a que, eso que usted llama pueblo, pueda no solo comprender en todos sus extremos, y en sus alcances, cuáles han sido las causas, los efectos y las consecuencias que nos han llevado a una situación que podemos entender como una erosión sistemática de nuestra democracia, sino que, además, no se ven acciones que sean congruentes por lo menos de manera mayoritaria y diseminadas en la 
geografía nacional, que permitan decir que tenemos un pueblo, o unas ciudadanías para hablar en plural, que sepan distinguir entre las claves de nuestro desarrollo, no solo democrático, sino de nuestro desarrollo humano construido con mucho esfuerzo hasta finales del siglo pasado. Me parece que hoy, como consecuencia de un sistemático proceso de ideologización, llamémoslo así, contrario a esa tradición civilista, democrática y de tolerancia, que ponía el acento y los énfasis de sus propuestas de desarrollo más en lo humano que en lo económico, pues evidentemente hoy tenemos como resultado una pasividad que viene construyéndose en los últimos treinta años.

Coincido con su planteamiento al decir que esta situación se ha incrementado a partir de las políticas públicas y de las visiones seudo estratégicas de los distintos gobiernos y administraciones, que lo que han hecho es seguir, sin ningún reparo o modificación y de manera ortodoxa, el llamado Consenso de Washington. Línea que imponía, como meta y propósito expreso, la reducción de la institucionalidad pública, la reducción del Estado y del espacio de lo público, así como llevar la toma de decisiones públicas a su mínima expresión. Esto era presentado como el requisito para un crecimiento económico y una mejor distribución de la riqueza, lo cual no ha sucedido, sino que, como ya sabemos, ha sido una promesa absolutamente falsa, incumplida y quizás, igualmente ideológica.

ML: La segunda pregunta contextual se enfoca precisamente en el tema institucional. Hace unas semanas, en la discusión sobre la Ley de Empleo Público (expediente legislativo 21.336) en la corriente legislativa, el rector de la Universidad de Costa Rica señalaba que "no es la Universidad de Costa Rica a la que se está poniendo en entredicho, sino su posición crítica” ¿Por qué razón o razones al Estado no le sienta bien, hoy, el papel crítico de las universidades?

RRV: Porque la universidad pública, por lo menos en este país, es quizás el último estandarte de criticidad y de resistencia intelectual frente a ese modelo que podríamos llamar, a mi juicio, hegemónico. Es uno de los pocos resabios, institucionales, que se ha resistido, de manera consistente, a aceptar el ideario del Consenso de Washington, sin que exista ningún filtro de criticidad y de propuesta alternativa. Sin embargo, hay facultades y colegas, e incluso grupos organizados dentro de la misma Universidad, que claramente han querido que este ideario sea implementado. Esto lo justifican, por supuesto, desde su propia visión epistémica e ideológica, neoliberal.

Entonces, no podemos afirmar que la Universidad en su totalidad asume esa posición crítica. La Universidad es, universalidad de pensamiento; pero sí podemos decir que, salvo esos pequeños grupos que se adhieren al modelo propuesto por el Consenso Washington, a la reducción del Estado a su mínima expresión y del espacio público, a la corporación de los intereses privados de ese espacio público, etcétera, la Universidad consistentemente y, de manera oficial, desde sus autoridades, se ha resistido a que la educación superior pública en nuestro país caiga en ese conjunto propagandístico de divulgación de esa ideología, llamémosla así, posdemocrática. Aquí quiero poner un énfasis particular. Primero que, hasta los noventa, América Central en particular, fue donde prácticamente se batió el último pulso, la última guerra de la Guerra Fría. Segundo, que si bien durante la Guerra Fría la democracia liberal fue aliada del mercado y le era funcional para el cumplimiento de los objetivos de acumulación de la riqueza que propone, y que los Estados eran afines a eso, lo cierto es que, para el Consenso de Washington y en general para el neoliberalismo, en sus expresiones concretas en la región y en particular en Costa Rica, en los últimos treinta años, la democracia dejó de ser funcional para el mercado y para el capitalismo global. Por el contrario, hoy, como se observa en muchos lugares, ese afán de expandir la democracia a formas más allá de las minimalistas, electorales o representativas, se constituyen en una amenaza para ese esfuerzo hegemónico del capitalismo global.

De modo que es importante decirlo, las universidades, entre otros actores y agencias políticas, se han decantado por la defensa de eso que llamamos el Estado democrático y social de derecho. Al hacerlo, anteponen los valores de democracia, de paz social, de desarrollo civilista y colocan lo humano antes que la economía. Este accionar entonces, las convierte en un enemigo al cual hay que reducir a su mínima expresión, hay que cortarle todas las posibilidades de generación de alternativas al modelo hegemónico lo cual es uno de los principales objetivos del 
Consenso de Washington hasta la fecha. Por lo tanto, la universidad pública seguirá siendo un aliado del proyecto contra hegemónico.

ML: Resulta claro que la educación siempre ha jugado un papel protagónico en la creación de conciencia en los muchachos jóvenes y especialmente en la universidad. Sin embargo, en algunos espacios usted ha señalado dudas o ciertas reservas sobre lo que se hace en Costa Rica en términos de la Educación Cívica. Quisiera que se refiera a ¿cuál es su opinión sobre lo que se está haciendo con los jóvenes en términos de formación ciudadana?

RRV: El sistema educativo, y esto no es un descubrimiento mío ni novedoso, desde la filosofía inspirada en el materialismo histórico y el marxismo del siglo XIX, pero con más énfasis durante la primera y segunda mitad del siglo XX, los autores como Louis Althusser, Nicos Poulantzas, etcétera, hablaban de los aparatos ideológicos del Estado, donde la educación cumple un rol fundamental para el mantenimiento del sistema. Hablamos del sistema capitalista, y particularmente en nuestros días, del sistema capitalista global.

Y la educación sigue cumpliendo ese papel. Por ello, lo que creamos es vital, igual que lo que hagamos o dejemos de hacer, como, por ejemplo, pensar críticamente y oponerse a la hegemonía. Eso es, justamente, lo que se quiere evitar que se haga, y se observa en los procesos formativos, formales e informales, desde la educación temprana y en las primeras etapas de socialización y secularización de los jóvenes. A ello contribuyen los hogares, las iglesias, etcétera; todo el entorno que rodea a los jóvenes, porque esa es la pregunta, no hace otra cosa más que reproducir, como parte de los aparatos ideológicos del Estado, las visiones que se consideran predominantes. En historia lo conocen muy bien, la historia generalmente es construida, impuesta por el ganador o los ganadores, y cuando hablo de los ganadores, nunca, mejor dicho, que al mencionar a los ganadores de ese modelo económico que han sido los menos, pero que tienen el poder de hacer que toda una sociedad siga su proyecto. Aunque esa sociedad claramente no es consciente de ello, al final se reproduce mucha mitología sobre la realidad de una nación, de un país que dejó de serlo desde hace más de treinta años. Dicho de otra manera, es necesario que se crea que seguimos siendo aquella nación; la condición de seguir viéndonos como ya no somos resulta vital para que se acepte la situación sin resistencia, sin criticidad. Pero, además, es funcional para que se descalifique como antisistémico e incluso antidemocrático, anti civilista y anti pacífico, cualquier respuesta o propuesta contundente que se plantee frente a esas pretensiones hegemónicas.

La clave para que el proyecto se imponga, de manera inconsciente y sin necesidad de utilizar la violencia directa, es a través de la resignación. Y ese es el verdadero problema hoy. El modelo de desarrollo que estamos siguiendo y el proceso de formación de personas en los distintos Estados, llamémoslo sistemas políticos, sistemas sociales, en Costa Rica, en Centroamérica y América Latina, al menos por los casos que conozco, implica la formación, no de personas ciudadanas, sino de consumidores dóciles y acríticos, pero integrados al sistema y esa es justamente la clave de los procesos educativos formales e informales, pero, sobre todo, los formales. Los pénsum, el currículo, los planes generales de implementación de los principales cursos y sus contenidos, tanto en primaria como en secundaria, tienen que seguir las disposiciones que definan las autoridades del sector educativo y eso ha sido así siempre. Me parece que, en los últimos treinta años, esas disposiciones claramente responden a la estrategia de pasividad y de introducción de visiones equivocadas sobre lo que debería ser nuestro desarrollo humano y estratégico, $y$, no obstante, son tremendamente funcionales para que lo aceptemos resignadamente. Su finalidad es que creamos que lo más importante en nuestra vida cotidiana y en nuestra vida profesional y laboral, en nuestra realización como personas humanas, son los valores derivados de ese ideario capitalista y neoliberal. Somos útiles y somos "exitosos" en la medida en que seamos consumidores como decía Göran Therborn, y no ciudadanos. Hoy formamos consumidores dóciles y no ciudadanía crítica. 
ML: ¿Podríamos decir que este proyecto incluye la conformación de una cultura política de la resignación? para usar tu concepto.

RRV: Claro. El miedo siempre ha sido efectivo en política. Sabemos que el miedo moviliza o desmoviliza, pero ahora pareciera que el signo de los tiempos, de eso que llaman la política posmoderna, no es el miedo sino la resignación, la aceptación dócil y el pensar que no hay alternativa. La distopía en lugar de la utopía, y eso nos enseñan de pequeños, se nos enseña a aceptarlo así. Eso sí, generándonos como paliativo, y como parte de esa mitología, un conjunto de derechos que creemos que podemos ejercerlos de manera igualitaria todas y todos Hay una visión de que la igualdad por sí misma en todas sus expresiones es un antivalor democrático, es más, atenta contra el desarrollo democrático y que cuando se quiso imponer fue propio de regímenes totalitarios y autoritarios. Por ello, la igualdad se debe reducir y se ha reducido, hasta la fecha en nuestros países, al aparente ejercicio, no igualitario, sino equitativo, de derechos. Esto implica sujetar nuestra condición de ciudadanía a lo que, justamente autores cómo Marshall habían advertido como pernicioso y malo hace unos setenta años, que era ver a las personas ciudadanas única y exclusivamente por sus posibilidades de ejercer derechos civiles y políticos.

ML: Esto que mencionas lo conecto con otra pregunta. $\mathrm{Al}$ revisar por ejemplo, la fundamentación del plan de estudios de educación ciudadana en Costa Rica, se percibe esa visión posmoderna, un poco recordando a Von Beyme, e incluso hasta una tendencia hedonista. De hecho, el programa plantea que la humanidad debe guiarse "por esas grandes fuerzas que la han guiado a lo largo de la historia, la ética y la estética, la búsqueda de lo que es bueno, qué es lo correcto y la búsqueda de que es bello" (Programa de Cívica, III ciclo y diversificado, p. 7). Ahí no aparece nada de criticidad ipodrían ser realmente estas las cosas que nos orienten en un contexto como en el que estamos viviendo?
RRV: Lo que voy a decir puede sonar contradictorio con lo que hemos discutido hasta este momento. Eso es bueno de inicio, pero es absolutamente insuficiente si eso significa el todo. Creo que es ahí donde está el juego político. Lo que acabas de anotar es casi poético, es como la aspiración de una realización plena que, a lo largo de distintas épocas de la humanidad se nos ha vendido como ideal, como utopía. Desde el Renacimiento, en la Ilustración, en la modernidad, la razón humana y la expresión de todas las dimensiones del ser humano, llevadas a su máxima expresión para cumplir con un plan, además universal de desarrollo equilibrado, en fin, un ideario bellísimo, en donde la ética y la estética juegan un papel fundamental. Yo no cuestionaría eso. Repito, ahí reside el verdadero juego político; se ha dejado de manera exclusiva y para efectos casi de realización existencial, este marco de referencia. Eso no está del todo mal, pues podríamos cambiar las formas en cómo hemos "aprendido" lo que es el arte y su importancia en la vida humana y en los procesos de formación cívica, pero la debilidad es que se ha dejado de lado los valores y la formación normativa, el compromiso cívico ciudadano, en función de intereses muchísimo más particulares e individualistas y amenazantes a la cuestión social.

Eso está bien recuperarlo e introducirlo dentro de los planes de estudios en la materia de Educación Cívica, por ejemplo, o de educación artística o de ética, que, dicho sea de paso, también es de reciente aparición en las discusiones educativas formales de nuestro país, propiamente con el proyecto de Ética, Estética y Ciudadanía impulsado por el ministro Leonardo Garnier, en la segunda ministración de Óscar Arias. Ahí se empiezan a discutir estos temas, pero, a mi juicio, como otro recurso de distracción y, por lo tanto, ideológico, para soslayar, y yo diría casi que aniquilar cualquier posibilidad de formación del otro pilar que contenía originalmente la propuesta, que era el fortalecimiento de las personas como ciudadanas, como personas ciudadanas de un país democrático. Entonces, lo único que quedó de esa buena intención, pero que fue útil para el proyecto hegemónico, fue decirnos que ahora íbamos a tener parte de una visión humanista más amplia en los procesos formativos de educación cívica de las personas jóvenes de nuestro país, 
gracias a las reformas en la ética y en la estética; pero ¿qué pasó con la parte de formación ciudadana? No quedó en nada; quedó básicamente en lo que he dicho que han sido los procesos de Educación Cívica en los últimos cincuenta años -y me incluyo en esa experiencia también- y es la simple repetición y la integración de mitos: el mito del IGUALITICO, el mito del pacifismo, el mito de la democracia eterna y, además, inexpugnable, sólida y siempre en proceso de fortalecimiento y sostenibilidad. En fin, la reiteración de una serie de prácticas que reproducen esos mitos sin ninguna criticidad.

ML: Quiero profundizar en algo que acabas de mencionar y es sobre la concepción de ciudadanía o Educación Cívica presente en el plan de estudios de Cívica del año 2009. Este programa, aún vigente, señala que ejercer la ciudadanía implica (Programa de Cívica, III ciclo y diversificado, p. 17)

Reconocer y valorar la política como una actividad necesaria para la vida colectiva.

Integrarse al sistema político, es decir, participar cuando lo considera importante y no disociarse ante la insatisfacción o pérdida de apoyo en algún nivel del sistema.

Buscar la propia libertad sin interferir con las de las otras personas.

Identificarse con su Estado, nación o comunidad política, reconociendo un sentido de pertenencia a una tradición histórica y un espacio compartidos.

Conocer y comprender los mecanismos institucionales para expresar apoyo o rechazo a las medidas que tome el Gobierno o para pedir su intervención en conflictos entre grupos o personas.

Escoger entre mecanismos representativos o participativos según la ocasión

Observar el cumplimiento de los deberes ciudadanos.

¿Es esto realmente un proyecto educativo? ¿O tiene más bien la lectura de un proyecto político? ¿Qué opinión le merece?
RRV: Esta línea es un proyecto político en donde lo educativo cumple un papel fundamental y es que no debemos disociarlo, la educación es política. Hay que decirlo y tomar conciencia de eso, pero decirlo y reconocerlo pareciera problemático, como si la educación formase parte de una producción no humana, sino angelical o extraterrestre. La educación es un proceso de producción humano y social que se corresponde con una determinada visión estratégica de sociedad; eso es lo que hace la educación. Entonces esos ítems (que son como un checklist) fue lo que terminó saliendo al final de ese proceso de discusión. Pero, cuando a Flor Isabel Rodríguez, politóloga, y a mi persona se nos convoca en el año 2007 para presentar un documento, conceptual, de cómo dos personas politólogas veíamos la formación ciudadana deseable para este país a mitad de la década tras anterior, empezamos a discutir lo político que es ese proyecto educativo, dichosamente. Pero hay que decirlo, el problema es que se contradice con ese primer postulado de la lista pues parece que no solo se ve erróneo, sino perverso pensar que la política y sobre todo la Educación Ciudadana, la formación ciudadana, es aséptica y no comprometida políticamente, pero no, todo lo contrario, y ahí es donde empieza el problema justamente. Esto soslaya el conflicto propio de la democracia, pues antepone la aceptación y la integración al sistema político, antes que la posibilidad, incluso, de disociarse en función del propio derecho a hacerlo.

Es interesante, y es propio de la política, cómo algo que originalmente fue pensado de una manera, termina siendo olvidado como dije al principio, soslayado o supeditado en el nivel de prioridades al último lugar y, paradójicamente, termina siendo funcional a lo que pretendió combatir. Por eso digo que ese proyecto de inicios del siglo XXI, que tenía tan buenas intenciones en formación crítica y constructiva -según lo discutido con Leonardo Garnier- terminó cayendo en el empedrado camino de las buenas intenciones. Pero hay otra razón y por eso hay que tener una visión crítica de conjunto. Quizás los primeros opositores a una reforma sustantiva de la Educación Cívica fueron nuestros queridos colegas docentes. El modelo ideológico impuesto por el Consenso de Washington y por el sistema capitalista global ha sido tan exitoso, que los encargados justamente de operacionalizar esas buenas ideas de formación cívica terminan igualmente resignados y resignadas, y les 
resulta terriblemente amenazante, para ese lado de confort y de resignación, cualquier reforma que les implique algún compromiso más allá de lo que tradicionalmente hacen. De ahí que las primeras discusiones en contra de la reforma a los planes en Educación Cívica, en Educación Musical, en Artes Plásticas, en fin, en Filosofía, Ética o Religión -todos incluían las dimensiones de ética, estética y ciudadanía- vinieron de los gremios de profesores de esas materias. Decían que era demasiado trabajo, y veían innecesario cambiar todo lo aprendido ya que hasta la fecha había resultado relativamente útil.

Fue de esta manera como, las buenas intenciones para reformar ese estado de situación fueron saboteadas por los verdaderos detentores del poder y por los interesados en que las personas seamos consumidores, no ciudadanos, pero contaron con la displicencia y, por lo tanto, complicidad y pasividad, de quienes deberían ser los verdaderos operadores del modelo, de los planes, de la ejecución de reformas en los planes de estudio y del ámbito curricular. Como resultado, este caso nos muestra lo exitoso que ha sido el modelo y el fracaso de cualquier intención de cambio que pueda tener la Educación Cívica en nuestro país, la reforma de Educación Cívica Ciudadana.

ML: Volviendo de nuevo al plan de estudios de Educación Cívica, en él se hablaba de que "hay prácticas que deben aprenderse, valga la redundancia, que deben practicarse, hasta que se vuelvan no solo entendidas y practicadas, sino casi intuitivas... el sentir democrático" (Programa de Cívica, III ciclo y diversificado, p. 9). Uno podría pensar que tal aseveración se relacionada, por ejemplo, con dinámicas como los procesos electorales en los sistemas educativos, la conformación de comités para que vayan asumiendo responsabilidades, representación, elección, etcétera. Pero más allá de estos elementos propios del sistema educativo, la pregunta puntual con la que quisiera cerrar esta conversación es ¿Cómo se aprende a ser ciudadano? ¿Cómo se aprende ciudadanía?

RRV: Se aprende ejerciéndola, así de sencillo. No es solo ni exclusivamente a partir del aprendizaje del derecho, del marco normativo mínimo y de la institucionalidad pública, de los aspectos formales y de los mecanismos formales con que nosotros podemos expresarnos con libertad, etcétera. Sabemos que eso es importante, pero es insuficiente. Esto no es algo reciente, sino que desde hace setenta años que se viene debatiendo y se sigue debatiendo sobre ciudadanía y sobre ciudadanía en democracias. No soy yo quien pueda, en estas líneas, dar ninguna cátedra pues hay gran cantidad de reflexiones alternativas a lo predominante y lo hegemónico, como las reflexiones de Samir Amin, las de Fernando Savater y de Fernando Bárcena. Hay una gran cantidad de posiciones que podrían utilizarse como referencia alternativa al modelo seguido hasta la fecha, pero todas tienden a coincidir en que la ciudadanía se aprende ejerciéndola, es una práctica. Esto ya había sido advertido desde otros influjos de pensamiento, como el de la cultura política y el del capital social, en particular, al plantearse cómo se crea un compromiso cívico, qué hace diferente a una sociedad cuyos ciudadanos, como por ejemplo en Suecia, Noruega o Dinamarca, etcétera, se comportan de "x" manera, tienen una visión de mundo, (nótese dónde está lo ideológico presente) una cosmovisión que es compartida independientemente de sus diferencias, porque se reconoce que el buen ejercicio ciudadano implica el reconocimiento y la defensa de la diferencia.

Pero creo que, en este país, y me parece que en América Latina, se ha combatido sistemáticamente la generación de un compromiso o proyecto cívico político común. Desde hace mucho rato no se tiene y ni siquiera se debate al respecto. Este país está tan resignado y tan dogmáticamente creyente que, 1) nuestra democracia y nuestra condición de ciudadanía en esta democracia es tan exitosa que nos va a garantizar el éxito futuro, por lo tanto, no debe tocarse; y, 2) quizás lo más complicado es que cualquier alternativa o propuesta contrahegemónica que se presente a ese proyecto es considerada disociación; se considera que la crítica es disociativa, que el conflicto es antidemocrático, que la diferencia hay que combatirla.

Esos son ejemplos de ideas que determinan o predeterminan las prácticas que posteriormente desarrollamos como personas y también como personas ciudadanas. La respuesta de que la ciudadanía se aprende ejerciéndola, lleva implícita la idea de que la mala forma de aprender ciudadanía se aprende justamente, a partir del criterio de que no hay que hacer nada. Vean que contradictorio, aprendemos que el buen ciudadano es aquel que acepta pasiva, y resignadamente, el estado de la situación 
de las cosas. Y que cuando se siente disconforme frente a eso, el medio que tiene para responder frente a esa situación es el derecho, pero otra vez se mitifica una construcción política estratégica como si fuera neutral, a sabiendas también de que el derecho tampoco es una creación de ángeles, sino de seres humanos y que es producido por una serie de fuerzas políticas que, en un momento determinado, indican qué es lo que hay que hacer y qué es lo que no se puede hacer. Eso no lo enseñamos en los procesos de Educación Cívica a las personas jóvenes, presentamos toda nuestra institucionalidad y nuestra historia como un producto mítico y no humano, no producto del conflicto, del debate y de la crítica.

Además, cómo podemos formar personas ciudadanas apostando, de forma exclusiva a los procesos educativos formales cuando tenemos familias autoritarias y acríticas, cuando en las comunidades, en nuestro relacionamiento cotidiano reproducimos esa idea hegemónica dominante. La educación formal, que forma parte del aparato ideológico del Estado y que tiene un papel determinante para cambiar o no el estado de las cosas, para resignarnos o no, para decir que la criticidad, o la disociación -es una posibilidad también- y el cambio a las reglas del juego también es una posibilidad. Se nos enseña exactamente lo contrario en todo esto, nos descalifican y se nos desmotiva y excluye o penaliza como hemos visto, de manera reciente, en las movilizaciones sociales que se han dado en el país, las cuales son, a priori, calificadas como antisistémicas y antidemocráticas. Nótese que el proyecto hegemónico con el que iniciamos la discusión no solo apuesta a la educación formal y a los procesos de "Educación Cívica" atróficos, distópicos, sino que también forma parte de un sistema de control y de dominación en el que la educación es quizás el eslabón más importante, pero es una más, junto a las otras instituciones sociales, la familia, las comunidades, los medios de comunicación, etcétera.

ML: Esto que acabas de plantear, nos deja también algunas reflexiones que hay que llevar a las universidades, a las escuelas que imparten las carreras de enseñanza de Estudios Sociales y Educación Cívica, pues creo que es necesaria una reflexión más profunda sobre el desarrollo de la Educación Ciudadana en Costa Rica, pero no desde los temas cívicos como ha sido la tradición, sino desde este perfil ciudadano, pues hay una diferencia epistemológica detrás de esto y todavía no se ve realmente plasmada en los planes de estudio. Pero bueno, ¿Quisieras agregar algo adicional a lo que has desarrollado hasta ahora?

RRV: Sí. Hay que apostar también a lo que ha funcionado en otros contextos y que no se nos ha permitido que funcione en el nuestro. Hablo de la educación popular. Boaventura de Sousa Santos habla de la Universidad del Pueblo, por ejemplo; ahí estamos mostrando posibilidades de formación ciudadana en la práctica, no en el simple aprendizaje reiterativo, mecanicista y sumativo que ustedes conocen bien, y que sabemos que son funcionales para el proyecto hegemónico, para la pasividad, para la resignación, para la formación estrictamente cívica y no ciudadana. Pero hay buenas prácticas desde la educación popular que deberían formar parte de la reflexión en los procesos formales, también de la nueva educación ciudadana que queremos implementar y que deberíamos aplicar para una democracia remozada. Una democracia que sepa resistir y responder al objetivo hegemónico del capitalismo global contemporáneo, que es, repito, generar sociedades, estados y un sistema que esté dominado, regulado y que tome decisiones por el colectivo, entiéndase política, desde la economía, el mercado y el liberalismo, y no desde la democracia.

En efecto, hoy lo que tenemos son sociedades, como la costarricense, posdemocráticas, sociedades liberales posdemocráticas -y con esto término, con una reflexión axiológica normativa, absolutamente valórica- y es que quizás el verdadero reto de la educación, más que la formación de personas ciudadanas, es que esta contribuya a crear un colectivo, una sociedad y un país, finalmente, democrático posliberal que volvamos a recuperar lo que ha sido clave para el mantenimiento de la convivencia humana a lo largo de los siglos y es, anteponer ese compromiso cívico, ese sentido de pertenencia y desarrollo de comunidad, antes que la economía, el mercado, el hedonismo y el individualismo, que es lo que observamos prevalente en las prácticas de eso que llamamos ciudadanías en nuestro país. 